\title{
Synthesis of a Disulfide Stabilized RNA Hairpin1
}

\author{
Jay T. Goodwin² and Gary D. Glick* \\ Department of Chemistry \\ University of Michigan \\ Ann Arbor, Michigan 48109-1055 U.S.A.
}

Key Words: Disulfide cross-link, RNA hairpin

\begin{abstract}
An N-3 ethylthiol-modified uridine has been syntherized and incorporated through solid-phase phosphoramidite chemistry at the 5'- and 3'-termini of an RNA hairpin to provide increased conformational
\end{abstract} stability via a disulfide cross-link.

The remarkable conformational diversity of RNA is manifested in the variety of its biological functions, such as in transfer, messenger and ribosomal RNA, and ribozymes. Hairpin loops contribute significantly to these structures and have been implicated as sites for protein binding and nucleation of RNA folding. 3,4 In particular, tetranucleotide

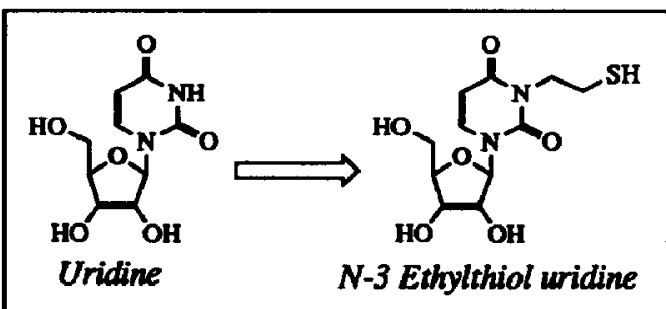
loop sequences UNCG and GNRA (where $N$ is any nucleotide and $R$ is purine) frequently occur in RNA hairpins and confer extraordinary stability to these structures.5,6,7 The UUCG tetraloop is found frequently within the mRNA of bacteriophage $\mathbf{T} 4,5$ and has been speculated to be a potential protein binding site for a variety of systems.5 To facilitate examination of the roles of hairpin loops and duplex major groove accessibility to protein recognition and binding, 89 we have incorporated a disulfide cross-link at the terminus of an RNA hairpin using an $N$-3 alkylthiol-modified uridine and demonstrate that this cross-link imparts added conformational stability. ${ }^{10,11}$ Cross-linking at the terminus does not disrupt Watson-Crick base-pairing, 12 and unlike cross-links positioned within the duplex ${ }^{13}$ does not potentially interfere with protein binding and hydration in the major groove.

The $N$-3 ethylthiol-modified uridine was synthesized by alkylation of transiently protected uridine14 to provide 1 in $63 \%$ yield (SCHEME I). Following tritylation ${ }^{15}$ of the 5'-hydroxyl group the thiobenzoate was converted to the $t$-butyl disulfide, 16,17 with subsequent monosilylation's to yield a mixture of $2^{\prime}$ - and $3^{\prime}$ - $O$ silylated intermediates 2 in $40 \%$ yield for three steps. The 2 - and 3'-isomers were separated by flash 
chromatography 18 and the 2'-silyl ether 3 was converted to the 3 '-phosphoramidite ${ }^{19} 4$ in $82 \%$ yield. ${ }^{20}$ To incorporate the modified uridine at the 3'-terminus of an RNA oligomer requires preparation of the appropriate nucleoside-modified resin. This support was synthesized by treatment of the 3'-silyl ether 5 with succinic anhydride and activation of the free carboxylate as the pentachlorophenyl ester, 6.21 Reaction of aminoalkylated controlled-pore glass ( $500 \AA$ ) with 6 provided the desired resin, 7, with a loading of $30 \mu \mathrm{mol} / \mathrm{g}$.<smiles>O=c1[nH]c(=O)n2n1CC(O)(CO)C(O)C2O</smiles><smiles>[Mg][Mg]</smiles>

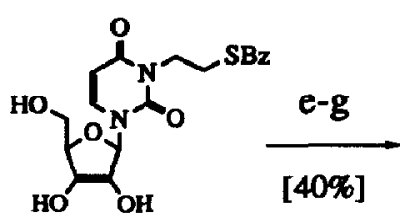

1

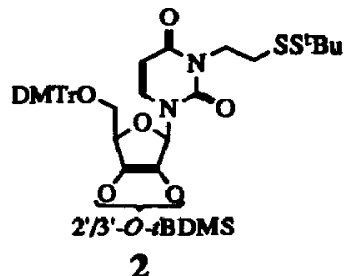

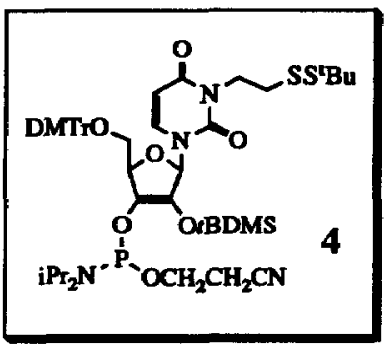

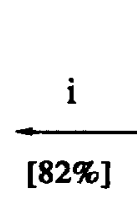

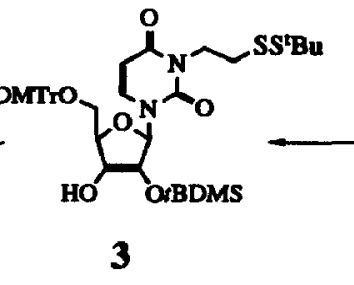

h [3:5 = 60:40]

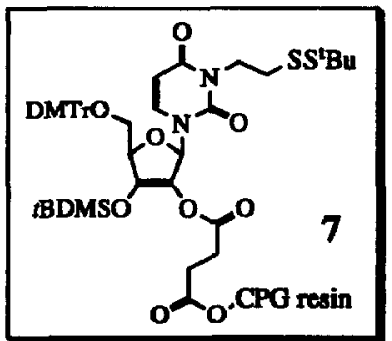

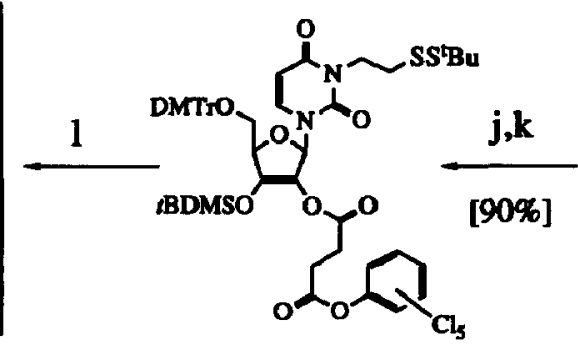

6

SCHEME I. (a) TMSCl, Et3N, DMF; (b) NaH, DMF; (c) pTsOCH $2 \mathrm{CH}_{2} \mathrm{SBz}$; (d) $\mathrm{HF}$ (aq.); (c) DMTrCl, pyridine; (f) 1-t-butylthiohydraxine-1,2-dicarboxmorpholide, LiOH, MeOH; (g) $t$-BDMSCl, imidasole, DMF; (h) flash chromatography; (i) 2-cyanoethyl- $N, N$-diisopropylchlorophosphoramidite, 2,4,6-collidine, $n$ methylimidazole, THF; (j) succinic anhydride, DMAP, pyridine; (k) pentachlorophenol, DCC, DMAP, MeCl2; (f) CPG resin, EtzN, DMF. 
The RNA sequence 5 -UGACUUCGGUCU $(U=N-3$ ethyl-t-butyldisulfide uridine) was chosen due to the availability of thermodynamic and NMR structural data for the parent UUCG RNA tetraloop hairpin (5'-GGACUUCGGUCC). ${ }^{7}$ Previous crystallization of this sequence resulted in a bulged duplex due to the requisite high salt and RNA concentrations utilized.22 Conformational homogeneity enforced by the disulfide cross-link will potentially address this problem for structure determination. The RNA was synthesized via solid-phase phosphoramidite chemistry on a Millipore Expedite synthesizer, followed by cleavage of the oligomer from the resin with anhydrous ethanolic ammonia at room temperature and removal of the base and phosphodiester protecting groups at $55^{\circ} \mathrm{C}$ for $12 \mathrm{~h}$. Treatment of the base-deprotected oligomer with tetrabutylammonium fluoride ( $1 \mathrm{M}$ in THF) at room temperature for $18 \mathrm{~h}$ to remove the 2 -silyl groups and desalting on a Qiagen $\mathbf{5 0 0}$ cartridge yielded the fully deprotected $t$-butyl disulfide RNA hairpin. Purification from failed sequences was achieved by anion-exchange HPLC with a Partisphere SAX column, eluting with a gradient of $15 \mathrm{mM}$ to $300 \mathrm{mM} \mathrm{KH} 2 \mathrm{PO}_{4}$ (pH 6.3) containing $20 \% \mathrm{CH}_{3} \mathrm{CN}$. Subsequent desalting was performed with a Waters $\mathrm{C}-18$ Sep-Pak, eluting with a $\mathrm{CH}_{3} \mathrm{CN}$ step gradient, obtaining the pure RNA hairpin in roughly $45 \%$ overall yield (based on a 1 momole scale synthesis). ${ }^{23,24}$

The $t$-butyl thiol protecting groups were removed by treatment of the $t$-butyl disulfide RNA hairpin with dithiothreitol (100 equivalents) at pH 8, $40^{\circ} \mathrm{C}$ for $12 \mathrm{~h}$ (monitored by reversed-phase HPLC on a Vydac C-4 column, eluting with a $\mathrm{CH}_{3} \mathrm{CN}$ gradient in $0.1 \mathrm{M} \mathrm{Et} 3 \mathrm{NHOAc}$, pH 6.6). This deprotection was followed by Qiagen cartridge purification which yielded the alkylthiol-modified RNA hairpin. Air oxidation of this material (5 hours, $\mathrm{pH} 8$ ) under conditions which favor hairpin formation ( $100 \mathrm{mM} \mathrm{NaH} 2 \mathrm{PO}_{4}, 1 \mathrm{mM}$ in RNA) provided the disulfide cross-linked hairpin as verified by a negative Ellman's test and native and denaturing polyacrylamide gel electrophoresis. ${ }^{10, b}$ Enhanced stability due to the disulfide is indicated by comparison of the UV thermal denaturation curves for the cross-linked and unmodified RNA hairpins; $T_{\mathrm{m}}$ for the disulfide cross-linked hairpin is $90^{\circ} \mathrm{C}\left(10 \mathrm{mM} \mathrm{NaH} 2 \mathrm{PO}_{4}, \mathrm{pH} 6.0\right)$, almost $20^{\circ} \mathrm{C}$ greater than for the unmodified hairpin $\left(72^{\circ} \mathrm{C}\right) .7,25$ Notably, the $T_{\mathrm{m}}$ for the tetraloop hairpin with the terminal $t$-butyl disulfide modified uridines is virtually identical with that for the wild type sequence, suggesting that the terminus of the RNA helix can accommodate a remarkable degree of steric bulk without adversely affecting its stability. ${ }^{100,12}$

In conclusion we have synthesized an N-3 ethylthiol-modified uridine and incorporated it at both the 5 and 3'-termini of an RNA hairpin to provide a disulfide cross-link. We have demonstrated that this cross-link 
imparts greater conformational stability to the hairpin, and as such will be useful in the study of protein-RNA and RNA-RNA recognition. Insuring conformational homogeneity for such structures should also assist greatly in NMR and crystallographic studies. $6,7,22$

\section{REFERENCES AND FOOTNOTES}

1. Supported by a National Science Foundation Young Investigator Award and an American Cancer Society Junior Faculty Research Award.

2. NIH Postdoctoral Fellow.

3. (a) Hamy, F.; et al. J. Mol. Biol. 1993, 230, 111, and references therein. (b) Wu, H.N.; Uhlenbeck, O.C. Biochemistry 1987, 26, 8221.

4. Noller, H.F. Ann. Rev. Biochem. 1984, 53, 119.

5. Tuerk, C.; Gauss, P.; Thermes, C.; Groebe, D.R.; Gayle, M.; Guild, N.; Stormo, G.; d'AubentonCarafa, Y.; Uhlenbeck, O.C.; Tinoco, I., Jr.; Brody, E.N.; Gold, L. Proc. Natl. Acad. Sci. USA 1988, 85, 1364.

6. Heus, H.A.; Pardi, A. Science 1991, 253, 191.

7. Varani, G.; Cheong, C.; Tinoco, I., Jr. Biochemistry 1991, 30, 3280.

8. For related use of a disulfide cross-link to examine protein-DNA interactions and induced fit, see: (a) Stevens, S.Y.; Swanson, P.C.; Voss, E.W., Jr.; Glick, G.D. J. Am. Chem. Soc. 1993, I15, 1585. (b) Swanson, P.C.; Cooper, B.C.; Glick, G.D. J. Immunol., manuscript in press.

9. (a) Weeks, K.M.; Crothers, D.M. Science 1993, 261, 1574. (b) Puglisi, J.D.; Chen, L.; Frankel, (a) Weeks, K.M.; Crothers, D.M. Science 1993, 261, 1574., (b) Puglisi, J.D.; Chen, L.; Frankel, K.; Climie, S.C.; Kuperman, R.; Lin, W.C.; Sumner-Smith, M.; Barnett, R.W. Nucleic Acids Res. 1993, 21, 2585. (d) Tuerk, C.; Gold, L. Science 1990, 249, 505.

10. (a) Glick, G.D.; Osborne, S.E.; Knitt, D.E.; Marino, J.P., Jr. J. Am. Chem. Soc. 1992, 114, 5447. (b) Glick, G.D. J. Org. Chem. 1991, 56, 6746. (c) Bannwarth, W.; Wippler, J. Helv. Chim. Acta 1990. 73. 1139 .

11. Intramolecular disulfide bonds in nucleic acids were originally reported by: (a) Lipsett, M.N. Cold Spring Harbor Symp. Quant. Biol. 1966, 31, 449 (b) Carbon, J.A.; Hung, L.; Jones, D.S. Proc. Natl. Acad. Sci. USA 1965, 53, 979.

12. Fraying of the terminal base pair is prevalent in most synthetic DNA and RNA duplexes and as such incorporation of the disulfide cross-link at this position does not neccessarily result in loss of a base pair. Furthermore, the presence of the terminal disulfide cross-link does not perturb adjacent base pairs (Cain, R.J.; Glick, G.D. manuscript in preparation).

13. Ferentz, A.E.; Keating, T.A.; Verdine, G.L. J. Am. Chem. Soc. 1993, 115, 9006, and references therein.

14. Ti, G.S.; Gaffney, B.L.; Jones, R.A. J. Am. Chem. Soc. 1982, 104, 1316.

15. Hakimelahi, G.H.; Proba, Z.A.; Ogilvie, K.K. Can. J. Chem. 1982, 60, 1106.

16. Goodwin, J.T.; Glick, G.D. Tetrahedron Lett. 1993, 34, 5549.

17. The $t$-butyl disulfide is stable to all conditions involved in solid-phase RNA synthesis and deprotection.

18. The 2'-silyl ether can be recovered by reconversion of the 3 '-silyl ether to the isomeric mixture with $\mathrm{LiOH}$ in MeOH.

19. Scaringe, S.A.; Francklyn, C.; Usman, N. Nucleic Acids Res. 1990, 18, 5433.

20. All modified nucleosides gave ${ }^{1} \mathrm{H}-,{ }^{13} \mathrm{C}-, 31 \mathrm{P}-\mathrm{NMR}$, and mass spectra consistent with the proposed structures.

21. Usman, N.; Ogilvie, K.K.; Jiang, M.-Y.; Cedergren, R.J. J. Am. Chem. Soc. 1987, 109, 7845.

22. Holbrook, S.R.; Cheong, C.; Tinoco, I., Jr.; Kim, S.-H. Nature 1991, $353,579$.

23. Composition of the modified RNA oligomer was verified by enzymatic degradation. 24

24. Gait, M.J.; Pritchard, C.; Slim, G. in Oligonucleotides and Analogues. A Practical Approach, Eckstein, F., ed.; IRL Press: New York; 1991, pp 25-48.

25. UV thermal denaturation studies were done without $\mathrm{NaCl}$; in the presence of $\mathrm{NaCl} T_{\mathrm{m}}$ for the cross-linked hairpin is $>100^{\circ} \mathrm{C}$. 